NBER WORKING PAPER SERIES

ASSET RETURNS, DISCOUNT RATE

CHANGES AND MARKET EFFICIENCY

Michael Smirlock

Jess Yawitz

Working Paper No. 1530

\author{
NATIONAL BUREAU OF ECONOMIC RESEARCH \\ 1050 Massachusetts Avenue \\ Cambridge, MA 02138 \\ December 1984
}

Assistant Professor of Finance, the Wharton School (University of Pennsylvania) and John E. Simon Professor of Finance, Washington University, respectively. The authors have benefitted from comments at an NBER Summer Institute and, in particular, from Takotoshi Ito. The authors are grateful to the Institute of Banking and Financial Markets, Washington University (st. Louis), for financial support. The research reported here is part of the NBER's research program in Financial Markets and Monetary Economics. Any opinions expressed are those of the authors and not those of the National Bureau of Economic Research. 
NBER Working Paper 非 1530

December 1984

\section{Asset Returns, Discount Rate Changes \\ and Market Efficiency}

\section{ABS TRACT}

The primary purpose of this paper is to reconcile the previous findings of discount rate endogeneity with the presence of discount rate announcement effects in securities markets. The crux of this reconciliation is the distinction between "technica?" discount rate changes that are endogenous and "non-technical" changes which contain some informative policy implications. In essence, we attempt to separate expected discount rate changes from unexpected changes, or equivalently, the expected component of discount rate changes from the unexpected component. If markets are efficient, the former should have no announcement effects while the latter may be associated with an announcement effect. Accordingly, the focus of the empirical analys is is on the interaction between discount rate exogeneity, the specific monetary policy regime, and announcement effects. In addition, we examine whether the behavior of these markets in the post-announcement period is consistent with the rapid price adjustment implied by market efficiency.

Michael Smirlock
Jess Yawitz
Washington University
St. Louis, MO 63130

(314) $889-6340$ 
Considerable empirical evidence has been presented (e.g., waud (1970)) to support the assertion that discount rate changes contain "announcement effects" concerning the future course of monetary policy which significantly affect security prices.' Roley and Troll (1984) contend that the validity of this assertion depends on the operating procedures employed by the monetary authorities. Specifically, they present an analytical framework which demonstrates that with a policy of interest rate targeting, which characterized open market operating procedures prior to october 1979 (pre-79), no meaningful announcement effects are possible since any effects on market rates would be offset by changes in the level of nonborrowed reserves. Under nonborrowed reserve targeting, which has characterized post-October 1979 (post-79) monetary policy, changes in discount rates affect interest rates directly via (at least) changes in the expected short-run money path. Consistent rith this view, Roley and Troll report no znnouncemont offerte from discount rate changes on the term structure of interest rates from September 1977 to October 1979, but a significant announcement effect over the October 1979 to October 1982 period characterized by increases (decreases) in bond yields being associated with discount rate increases (decreases). Pearce and Roley (1984) report similar results for stock returns over the identical time period. Specifically, they find no announcement effect in the preOctober 1979 period, but significant negative (positive) stock returns associated with the announcement of discount rate increases (decreases) in the later period.

One difficulty with these studies is the assertion that discount rate changes are unexpected; that is, discount rate changes are exogenous. This is in contrast to both Lombra and Torto (1977) and Froyen (1975) who present evidence that the discount rates is a function of open market interest rates 
and member bank borrowing. Santomero (1983) and the papers cited therein describe current discount rate policy as passive and responding with a lag to changes in open market rates. The evidence from these studies suggest that discount rate changes are endogenous, and that even if these changes coincide with a recent revision in monetary policy objectives, the policy revision would already be incorporated into market yields. There would be no announcement effect under either operating procedure, since no new information is provided by the announcement.

The presence of an announcement effect associated with an endogenous (anticipated) discount rate change suggests that securities markets may not be (semi-strong) efficient. Such a finding would be in stark contrast to the numerous studies that either assume market efficiency for the purpose of hypothesis testing or provide empirical evidence in support of market efficiency. 2 Further, the usefulness of the discount rate as a monetary policy instrument is questionable if endogenous changes generate announcement effects.

The primary purpose of this paper is to reconcile the previous findings of discount rate endogeneity with the presence of discount rate announcement effects in securities markets. The crux of this reconciliation is the distinction between "technical" discount rate changes that are endogenous and "non-technical" changes which contain some informative policy implications. In essence, we attempt to separate expected discount rate changes from unexpected changes, or equivalently, the expected component of discount rate changes from the unexpected component. If markets are efficient, the former should have no announcement effects while the latter may be associated with an announcement effect. ${ }^{3}$ Accordingly, the focus of the empirical analysis is on the interaction between discount rate exogeneity, the specific monetary policy 
regime, and announcement effects. In addition, we examine whether the behavior of these markets in the post-announcement period is consistent with the rapid price adjustment implied by market efficiency.

The remainder of this paper is organized as follows. Section II presents a brief discussion of the theoretical link between discount rate changes and market returns as well as a description of the data and methodology. Preliminary tests reported in this section using our longer sample period confirm the Roley and Troll and Pearce and Roley findings: a significant announcement effect characterizes the post-79 period but there is no reaction of securities markets to discount rate changes in the pre-79 period. The next two sections refine the analysis to distinguish between technical and nontechnical discount rate changes. Section III provides a description of the classification scheme that we employ to identify technical and nontechnical aiscounc race ciranges. Section IV extenas lise empirical tests of section II using this classification. We find that in the pre-79 period there was no securities markets response to either technical or nontechnical changes while in the post-79 period there was no response to technical changes. Only nontechnical changes occurring in the post-79 period were characterized by significant announcement effects. In section $V$ we test and find that there is some evidence of a significant price adjustment in the day immediately following the actual announcement, but no price adjustment beyond this first day. Section VI contains our summary and conclusions.

II. Theoretical Framework and Preliminary Results

Discount rate changes will affect market rates and equity returns if such changes convey new information about either short or long-run monetary policy objectives. Roley and Troll argue that an increase in the discount rate that changes the implied short-run money path would be associated with an objective 
of returning to an implied long-run money. growth path more quickly. As a result, current (spot) and expected short-term rates rise in reaction to reduced short-run money growth. Long-term rates and forward rates may also increase to reflect the higher expected short-term rates. The opposite effect on interest rates is expected for discount rate decreases. An increase in the discount rate that changes only long-run monetary policy objectives would be associated with a decline in long-run trend money growth, reducing expected inflation and lowering future expected short-term rates. This implies no change in current short-term rates and a decline in long-term rates and forward rates. The opposite is expected for discount rate declines. If the perception of both short and long-run policy objectives is changed, a discount rate increase (decrease) may be expected to be associated with an increase in short-term rates but an ambiguous effect on forward rates and long-term

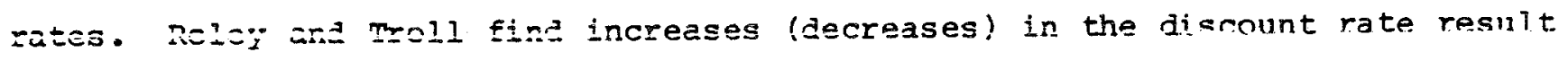
in increases (decreases) in short-term and long-term rates, leading them to conclude that the observed announcement effect is associated with changes in short-run monetary policy objectives.

The impact of discount rate changes on equity prices can operate through two possible channels. This is most readily seen by viewing the value of the firm as the present value of its future net cash flows. To the extent discount rate increases (decreases) result in increases (decreases) in interest rates, the rate at which the firm's cash flows are capitalized will rise (fall) with a subsequent negative (positive) effect on stock prices. Additionally, discount rate changes can alter expectations of future cash flows. Specifically, discount rate changes that increase or decrease real economic activity will alter cash flow expectations in the same direction. One would expect that to the extent both capitalization rates and cash flow 
expectations are affected by discount rate changes, these effects will work in the same direction. 4 Given the Roley and Troll findings discussed above, we expect stock price declines to be associated with discount rate increases, a finding that would be in agreement with the results reported by Pearce and Roley.

To assess the impact of discount rate changes on interest rates and stock prices, we utilize an event-time methodology that is similar to that employed by Roley and Troll in their paper and by Urich and Wachtel (1981), Roley (1983) and Pearce and Roley (1983) in their studies of financial market reaction to money supply changes. The following model is estimated

$$
\Delta R_{i t}=\alpha+B \Delta R D_{t}+\varepsilon_{t}
$$

where $\Delta R_{i t}$ is the percentage change in the relevant interest rate or in stock prices observed on announcement day $t$ of a discount rate change and is measured from the close of day $t-1$ to the close of day $t . \Delta R D_{t}$ is the percentage change in the discount rate announced on day $t$. For the purposes of this study, the announcement day is the day the discount rate change was reported in the Wall Street Journal. Our tests for differences in financial market reaction according to technical or nontechnical classification, as well as the investigation of financial market speed of adjustment issue use variants of (1) that are described in the following sections. The time period for this study is the eight year period from $1975-1982$ (no discount rate changes in 1983). Over this period there were 36 discount rate changes, 18 of which occurred prior to October 1979. Twenty-three of these changes were increases and 13 were decreases. Table 1 provides a rreakdown of the discount rate change data based on the size of the change and the period in which it occurred. The data indicate a clear shift toward 
larger absolute changes in the post-79 period as the average change increased from 43 to 82 basis points.

The stock return data is the daily percentage return on the New York Stock Exchange value weighted index and is denoted SP. The interest rate data are for constant maturity Treasury securities and include eight different maturities: 90, 180 and 360 day bills and three, five, seven, ten and twenty year bonds. These rates are obtained from DRI, who compile them from the Federal Reserve Board Statistical Release H.15. These eight interest rates are used to calculate seven forward rates in addition to the 90 day bill rate. Using forward rates avoids confounding the effect of discount rate changes on short-term rates with the effect on long-term rates, since movements in short-term rates will be reflected in movements in long-term rates, and allows more direct assessment of the effect of discount rate chenges on the term structure. These Eorward fates ars denctsd $\mathrm{x}^{\text {F }} \mathrm{y}$ and are read as the interest rate $x$ periods hence on a security with maturity $y$. Finally, it has been shown (e.g., Yawitz (1977)) that under quite reasonable theoretical specifications the risk and maturity structure of interest rates is better modelled in terms of the so-called discount factor, which is simply one plus the rate of interest. Accordingly, the percentge changes in both the interest rate and discount rate series are calculated as the percentage change in one plus the interest rate. 5

As an initial test, we estimate equation (1) over the pre-79 and post-79 periods for each of nine return series. 6 The estimates of the market response coefficient $\beta$ are reported in Table 2 . Our results confirm the Roley and Troll and Pearce and Roley findings. For the equity series, there is no significant market response in the pre-79 period but over the post-79 period there is a significant negative (positive) response to discount rate increases 
(decreases). The magnitude of the response coefficient suggests that a 100 basis point change in the discount rate results in approximately a one percent change in stock prices on the announcement day, almost identical to the magnitude reported by Pearce and Roley.

A similar finding is reported for the interest rate data. Only one interest rate series evidences a significant market reaction in the pre-79 period, while six of the eight interest rates indicate a significant market response over the post-79 period. 7 The pattern of coefficients suggests a larger effect on short-term rates than on Eorwara rates with a positive response on each rate. This finding supports the view that discount rate changes affect expectations about short-run monetary policy objectives. Finally, the magnitude of the response coefficients mirror that of Roley and Troll and suggest, for example, that a 100 basis point increase in the Cisconunt rate will increase the $90 \mathrm{~T}$-Bill rate and $10^{r_{10}}$ by approximately 50 and 18 basis points, respectively. 8

Although the above results confirm earlier findings, the real issue is whether the observed announcement effect, regardless of the monetary policy regime, indicates a market inefficiency. If, as available evidence indicates, the discount rate is endogenous, then the market may be inefficient since it significantly reacts to an event that should contain no new information. The hypothesis of this paper is that not all discount rate changes are entirely endogenous and those that are not may provide securities markets with new information that will lead to an adjustment in prices. Financial markets will be considered inefficient only if technical discount rate changes are characterized by announcement effects. 
III. Classification of Discount Rate Changes

The previous discussion clearly indicates that to properly assess the announcement effects of discount rate changes it is necessary to distinguish technical from nontechnical changes. Roley and Troll recognize this and attempt to explain daily discount rate changes via a regression equation, relating such changes to changes in the Fed Funds rate. Due to the low explanatory power of the equation, they are led to conclude that the entire change in the discount rate is unexpected; that is, all discount rate changes are nontechnical. 9 This finding is also used by pearce and Roley to justify their assumption of discount rate exogeneity.

There are several shortcomings with this approach, however, that limit its usefulness in predicting discount rate changes and cast substantial doubt on the assumption of discount rate exogeneity. First, the current method of changing the discount rate requires the approval of the Executive Committee of the Federal Reserve Bank's board of directors, which are contacted by phone every two weeks. Accordingly, the discount rate can only be changed at most one day every two weeks. This implies a daily model of discount rate changes is, in some sense, attempting to capture a biweekly event so that such a model is unlikely to yield good forecasts. A second shortcoming is the tenuous nature of constructing any reduced form model. This is particularly important in modelling discount rate changes where there are nonquantifiable factors, such as public statements by Federal Reserve officials, that may affect expectations concerning discount rate changes. Third, given the discrete nature of discount rate changes and the volatility of the Fed Funds rate, it is also not surprising that both the explanatory and predictive power of such an equation is low. Indeed, despite the infrequent changes in the discount rate, the extent of Fed Funds variability suggests that non-zero predictions 
of discount rate change are present for every day. Finally, as suggested by points one and three, the inability to forecast the precise day of a discount rate change, as such models attempt to do, does not necessarily mean that changes in the discount rate are mostly unexpected, but only that their exact timing cannot be predicted.

Given the above, we rely on two different methods to classify discount rate changes. The first is a statistical model that attempts to avoid or at least mitigate the shortcomings of the Roley and Troll discount rate change model. In our approach, we use weekly and not daily data, since the former is more consistent with Federal Reserve operating procedures. If the model specification is $\triangle R D=f(\cdot)$, then the anticipated or technical component of an actual discount rate change is $f(\cdot)$ and the unanticipated or nontechnical component is $\Delta R D-f(\bullet)$, which is simply the error term from the model. To translate the forerasts to daily forecasts we assume that a discount rate change predicted in week $t$ is anticipated regardless of the day in week $t$ it is actually announced and an unanticipated discount rate change in week $t$ is a surprise regardless of the day it is announced.

Several different specifications were estimated, including variants of those used by Roley and Troll, Lombra and Torto and by Brown (1981). One notable finding is the rejection of model stability over the pre-79 and post79 periods. In all cases, the mean square error was at least twice as large in the latter period. The best model, both in terms of in-sample fit and predicting actual discount rate changes, related changes in the discount rate (measured in basis points) to the spread between the Fed Funds rate and the discount rate (denoted SPREAD) over the last four weeks and changes in member bank borrowing, calculated for week $t$ as the change in borrowing from week $t-1$ to $t$ (denoted BORROW), over the last four weeks. The results of this model 
estimation are reported in Table 3. Although still low, the explanatory power represents a substantial improvement over Roley and Troll. Given the discrete nature of discount rate changes it is not surprising that the magnitude of actual discount rate changes is always underpredicted. Nonetheless, if the model incorporates the relevant information set, then by construction the forecasts are optimal predictions based on available information and, therefore, rational.

The second method for classifying discount rate changes is much simpler and more straightforward. When the Federal Reserve Board changes the discount rate, it states the reason for its action in a press release at the time of the discount rate change. For the purpose of this paper, technical changes are those purportedly taken entirely to bring the discount rate in closer alignment with money market rates. All other changes, even if they are described by the press relazsa as nredominantly for technical reasons, are classified as nontechnical.

Two points about this second methodology and its implications need to be made. First, it implicitly assumes the reasons given by the Fed are accurate or at least that the market perceives that they are accurate. As a check, the interpretation presented in the wall street Journal, which may more accurately reflect the market's perceptions, was also examined. For the time period 1971-1980, only one discrepancy was found. Therefore, use of the press releases for classification seems appropriate. ${ }^{10}$

Second, many of the changes classified as nontechnical also are at least partially technical in nature according to the press releases. For example, the rationale given for the discount rate change on september 22 , 1978 was "to bring [the] discount rate in closer alignment with short-term interest rates, and as a further step to strengthen the dollar." This clearly contains both 
technical and nontechnical elements. Accordingly, one possible explanation for the endogeneity-announcement effect anomaly is that the endogeneity finding reflects technical changes and the technical elements of nontechnical changes, while the nontechnical changes are responsible for the observed announcement effect. Our criteria for a discount rate change to be classified as technical has the effect of biasing against a finding that nontechnical changes exert a stronger effect on financial markets.

These two technologies for classifying discount rate changes are distinct in that the statistical method explicitly divides every discount rate change into a technical and a nontechnical component, whereas our specification of the "Federal Reserve announcement (FRA) classification method" classifies the entire change as either technical or nontechnical. Since discount rate changes generally consist of both technical and nontechnical components, it is tempting to assert the superiority of the statjstiral methnd. riven the difficulties in modelling discussed above, however, the Federal Reserve announcement classification method may provide a more accurate decomposition of discount rate changes. It is an empirical question as to which is the superior approach. ${ }^{11}$

Despite the differences in determining technical and nontechnical composition, if both classification schemes reflect market expectations then there should be some degree of consistency across the models. That is, if the statistical method indicates that a large percentage of a discount rate change is unanticipated (anticipated) then we would expect the FRA method to classify the change as nontechnical (technical). If this is true, the correlation coefficients between the percentage of a discount rate change classified as technical under one method with the percentage of a discount rate change classified as nontechnical under the alternative method should be negative, 
while the correlation coefficients of like classifications between methods should be positive. This is, in fact, the case. The former correlation coefficients are -.442 and the latter are .442 .12

IV. Empirical Results

of the 18 pre-79 discount rate changes, 11 are classified as nontechnical, while of the 18 post-79 discount rate changes, 12 are classified as nontechnical. 13 To begin the analysis, equation (1) is respecified to capture the technical/nontechnical classifications:

$$
\begin{gathered}
\Delta R_{i t}=\alpha+B_{T} \Delta R_{t}^{R D T}+B_{N T} \Delta R D N T T_{t}+u_{t} \\
\Delta R_{i t}=\alpha^{\prime}+B_{T}^{\prime} \Delta D_{t}^{R T_{t}^{*}}+B_{N T}^{\prime} \Delta D_{t}^{R D T}+u_{t}^{\prime} .
\end{gathered}
$$

In (2a), RDT (RDNT) is that amount of a given discount rate change that is classified as technical (nontechnical) according to the statistical model. In (2b) $T(N T)$ is a dummy variable equal to one if the discount rate change is classified as technical (nontechnical) according to the FRAC method and zero otherwise. All other variables in $(2 a)$ and $(2 b)$ are as previously defined. our expectations about the coefficient $B_{T}$ and $\beta_{N T}$ in the pre- and post-79 periods form directly from the monetary policy regime and market efficiency propositions stated earlier. Under the pre-79 interest rate targeting regime, we expect $B_{T}=\beta_{N T}=0$ since, regardless of classification, a discount rate change is not required, and will not by itself change the level of market interest rates. Given the results reported in Table 2, for the post-79 period we expect $\beta_{T}=0$ for both interest rates and equity prices and $B_{N T}>0$ for interest rates and $B_{\mathrm{NT}}<0$ for the equity return series. The expectations of $B_{T}^{\prime}$ and $\beta_{\mathrm{NT}}^{\prime}$ are the same as for $\beta_{\mathrm{T}}$ and $\beta_{\mathrm{NT}}$, respectively. 
The results of estimating equations (2) for the two subperiods are reported in Table 4. For the pre-79 period there is virtually no evidence of announcement effects, regardless of either classification or the classification method. When $(2 a)$ is estimated, only four of the response coefficients are significant at the ten percent level and one at the five percent level. Of the three significant coefficients on $\triangle R D N T$, only one has the theoretically expected positive sign. Using the FRA method, in only two instances is $B_{\mathrm{T}}^{\prime}$ or $\beta_{\mathrm{NT}}^{\prime}$ significant and the coefficient associated with nontechnical changes has the wrong sign. As expected, discount rate changes, regardless of whether or not they are anticipated, do not affect market rates under interest rate targeting (pre-79).

A different picture emerges from the post-79 period. The $\mathrm{R}^{2}$ of virtually every equation is higher than that reported in Table 2, indicating that aủitioña information is provided when discount rate changes are separated into technical and nontechnical changes. 14 For six of the eight interest rates the market response coefficient to nontechnical discount rate changes is positive and significant at the five percent level. In no case is the response coefficient positive and significant at even the ten percent level for technical changes. For equity returns, there is a negative and significant effect of nontechnical changes, but no significant stock market reaction to technical changes. These statements are accurate for both classification methods. Not surprisingly, for the seven significant response coefficients, both $\beta_{\mathrm{NT}}$ and $\beta_{\mathrm{NT}}^{\prime}$ are larger (in absolute value) than the response coefficients reported in Table 2 . While the results reported in Table 2 mirror Roley and Troll and Pearce and Roley in implying a 100 basis point increase in the discount rate results in a 50 basis point increase in $\mathrm{R}_{90}$ and $\mathrm{a}$ one percent decline in stock prices, we find that nontechnical 
increases of identical magnitude increase $R_{90}$ by 70 basis points and reduce stock prices by 1.6 percent.

These results provide strong support for the hypothesis that the market responds differently to discount rate changes depending on whether they are viewed as technical or nontechnical. That is, there is a significant announcement effect associated with discount rate changes that provide the market with new information, while there is no discernible announcement effect associated with technical discount rate changes. This finding is consistent with and supports the existence of the semistrong form of market efficiency. The results provide an explanation of the apparent anomalous finding of an endogenous discount rate coexisting with announcement effects. Technical discount rate changes are, by definition, endogenous. Nontechnical discount rate changes actually consist of both technical and nontechnical elements. xeccraingi\%, it is not surprising that discount rate changes as $a$ whole fail tests of statistical exogeneity. On the other hand, the announcement effect reported here and in previous studies for the post-79 period for discount rate changes as a whole seems to be due to inappropriately treating all discount rate changes the same. Specifically, the results of this paper suggest that the observed announcement effect is due only to nontechnical elements while the technical elements do not generate a market reaction. The discount rate endogeneity-announcement effect anomaly is not an anomaly at all and is simply due to a misspecification. ${ }^{15}$

Finally, the strength of these results is also reflected in the consistency of the findings across discount rate change classification methods. In addition to yielding virtually identical qualitative results, the coefficients $\beta_{N T}$ and $\beta_{N T}^{\prime}$ are similar for every asset price and in no case can the null of equal coefficients be rejected. Despite the similarity, however, 
it is of interest to see whether one model dominates the other. A cursory examination suggests the FRA classification method is superior to the statistical classification method since, as measured by the $R^{2}$, the former explains a higher variation of movements in asset price in all cases but one. To formally compare model structure, we employ the pairwise test of alternative hypotheses suggested by Davidson and Mackinnon (1981) and utilized by Urich and wachtel (1984) to compare expectations models of money supply announcements. This test asserts that if there are two model specifications given by $y=\hat{I}(\cdot)$ and $y=g(\cdot)$, then the nuli hypothesis that the first specification is true can be tested by estimating the model

$$
y=\hat{f}(\cdot)+\hat{y}_{g}
$$

where $\hat{y}_{g}$ is the predicted value from $y=g(\cdot)$. If the first specification f(.) is true (rolative to tho altoxactios $g($,$) ), than w will not be$ significantly different from zero. Of course, both models can be accepted as "true," just as each model can add explanatory power to the other and hence be said to dominate the other.

The t-statistics for the pairwise specification tests are given in the last two rows of Table 4 , with the model for the null hypothesis listed at the left. These test statistics indicate that with one exception neither model can be said to dominate the other. It should be noted, however, that in all but one case the test statistic is higher when predictions from the FRA are added to the statistical model than vice-versa. We view this as additional weak evidence in favor of the FRA method.

V. Speed of Asset Price Adjustment

As previously noted, an efficient market adjustment implies that there should be no response of asset prices to discount rate changes in the post- 
announcement period. We define the post-announcement period as the five trading days immediately following the announcement day $t, i . e .$, days $t+1$ to $t+5$. These five days correspond to the first trading week after the discount rate change announcement. Equations (2) were then reestimated using five alternative dependent variables to reflect asset price changes on days $t+1$ through t+5. Accordingly, $\Delta R_{i t+j}$ is defined as the percentage change in the relevant interest rate or stock prices observed on the $j^{\text {th }}$ day after a discount rate change and is measured from the close of day $t+j-1$ to the close of $t+j$. Based on the comparison of model structure reported above, we describe and report the results only for the FRA method, while noting that the statistical method yielded virtually identical results for each method.

Given the findings reported in Table 4 , our primary concern and interest is with nontechnical changes occuring in the post-79 period. The results from the other three classifications can be easily summarizod and hence aro not reported in a table. Of the 45 response coefficients estimated each for technical changes in the pre- and post-79 period, only one is significant at the five percent level. For pre-79 nontechnical changes, only 4 of the 45 response coefficients are significant at the five percent level and one of these has the wrong sign. For each asset and classification, F-statistics based on the null hypothesis that the sum of the response coefficients over the post announcement period equals zero were calculated. In no case could this null hypothesis be rejected at even the ten percent level.

In Table 5 we report the response coefficients and F-statistics for the classification of primary interest, nontechnical post-79 discount rate changes. For the day following the announcement, four of the interest rate and the stock price coefficients are significant at a minimum of the ten percent level. 16 This day $t+1$ price response was also found by Pearce and 
Roley for stock price adjustment to discount rate changes. For days $t+2$ through $t+5$, only 3 of a possible 40 response coefficients are significant at the five percent level, and one of these has the wrong sign. Because of the number of coefficients estimated over the post-announcement period, the statistical significance of any small set of coefficients should be interpreted cautiously. In particular, the number of statistically significant coefficients we found for days $t+2$ to $t+5$ would be expected even if no actual relationship exists. A more convincing test of slow price adjustment is the F-statistic based on the null hypothesis that the response coefficients over the post-announcement period sum to zero. These test statistics for nontechnical post-79 changes are reported in the last row of Table 5. In no case can the null of no asset price reaction be rejected at the five percent level. Overall, the empirical results described above and reported in Table 5 provide strong support for the rapid price adjustment associated with market efficiency and indicate that, to the extent markets react to discount rate changes, the reaction is largely complete by the end of the announcement day and certainly complete by the end of day $t+1$.

VI. Conclusions

The purpose of this paper has been to reconcile previous findings of both an endogenous discount rate and discount rate announcement effects with market efficiency. By classifying discount rate changes as either technical or nontechnical, and recognizing that the latter are (at least) partially endogenous, it is argued that the discount rate can fail tests of statistical exogeneity and still exhibit announcement effects within the framework of market efficiency. To be valid, however, only nontechnical discount rate changes should exhibit announcement effects. ${ }^{17}$ Combined with the evidence that the potential for announcement effects associated with discount rate 
changes depends on the monetary policy regime, the implication is that only nontechnical post-79 discount rate changes should yield announcement effects. The empirical evidence of this paper supports this view and suggests previous studies were misspecified by not controlling for the purpose of the discount rate change.

The evidence also implies that the common assumption, contained in virtually all theoretical and empirical macroeconomic models, that the discount rate is either purely endogenous or purely exogenous, is inappropriate. In addition, our findings may have some bearing on the continuing debate over the usefulness of the discount rate as a tool for macroeconomic policy. One argument against its use has been that it can generate perverse announcement effects because the public, as waud (1970, p. 250) states, reads "broader economic implications into even 'routine technical adiuatments." "The evidence here indicates that this is not the case. Markets react only when there appears to be a shift in policy--which is when a market reaction is desirable--and not to technical adjustments in the discount rate. At least from this standpoint, one cannot rule out the discount rate as a useful tool of monetary policy.

Finally, our results support the existence of efficient markets based on the dual finding that only nontechnical changes are characterized by announcement effects and that virtually the entire market adjustment occurs by the end of the announcement day. 
TABLE 1

The Size of Discount Rate Changes, Pre-79 and Post-79

\section{Discount Rate \\ Change (basis points)}

25

50

100

Average

(basis points)
Pre -79

7

10

1

43
Post-79

0

7

11

82 


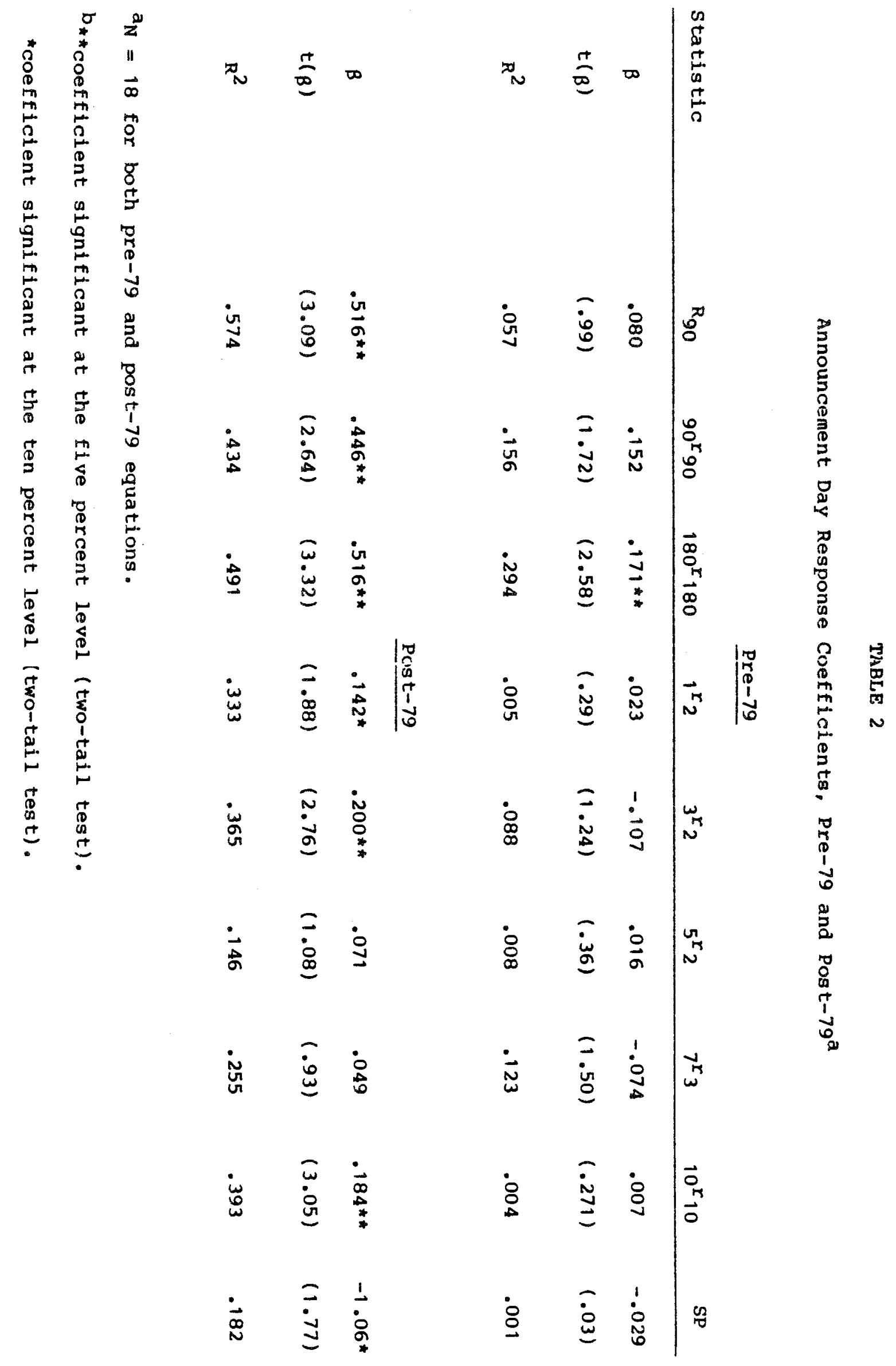




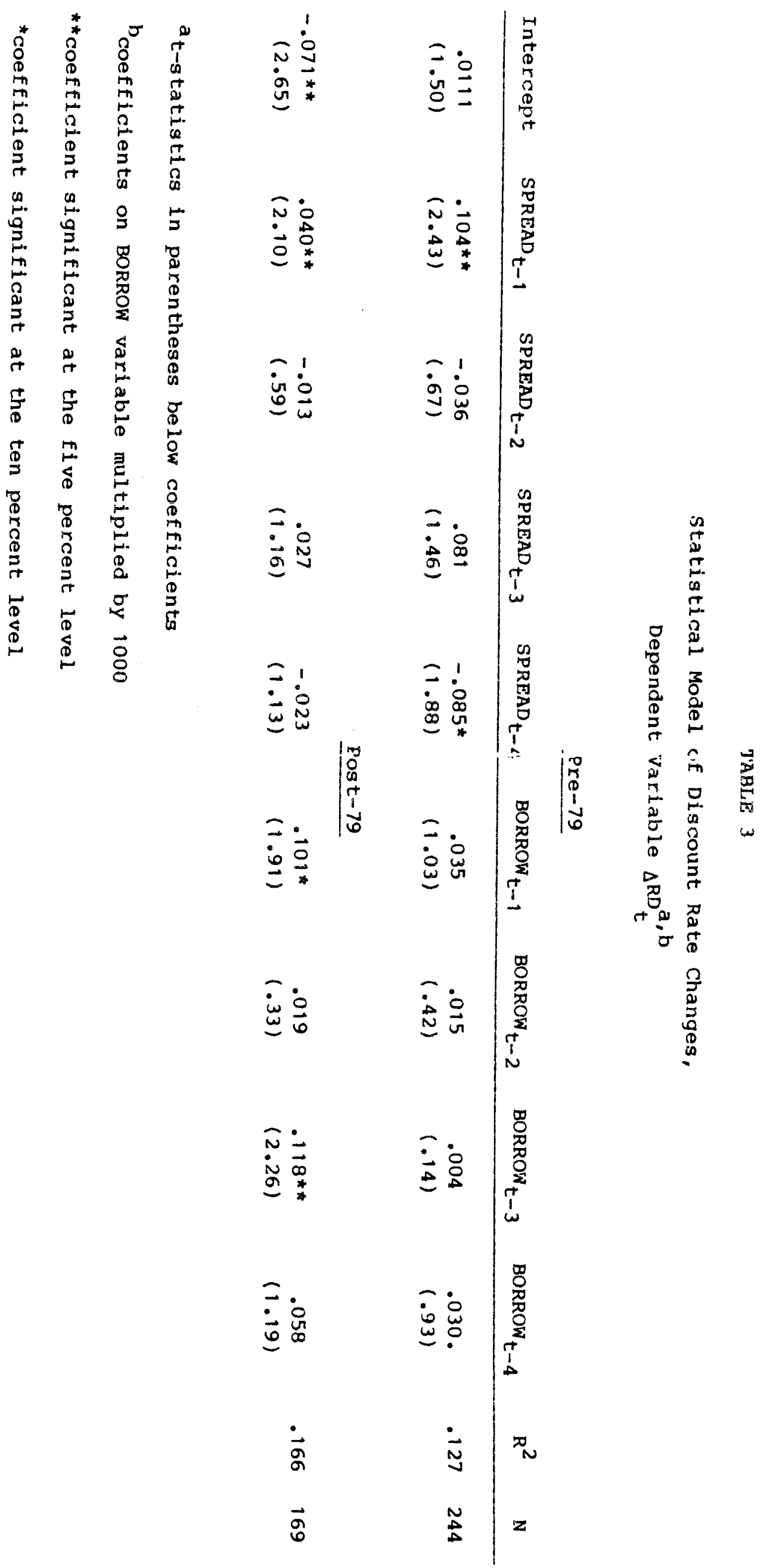


TABLE 4

Announcement Day Response Coefficients for Technical and Nontechnical Changes, Pre-79 and Post-79a,b

Pre-79

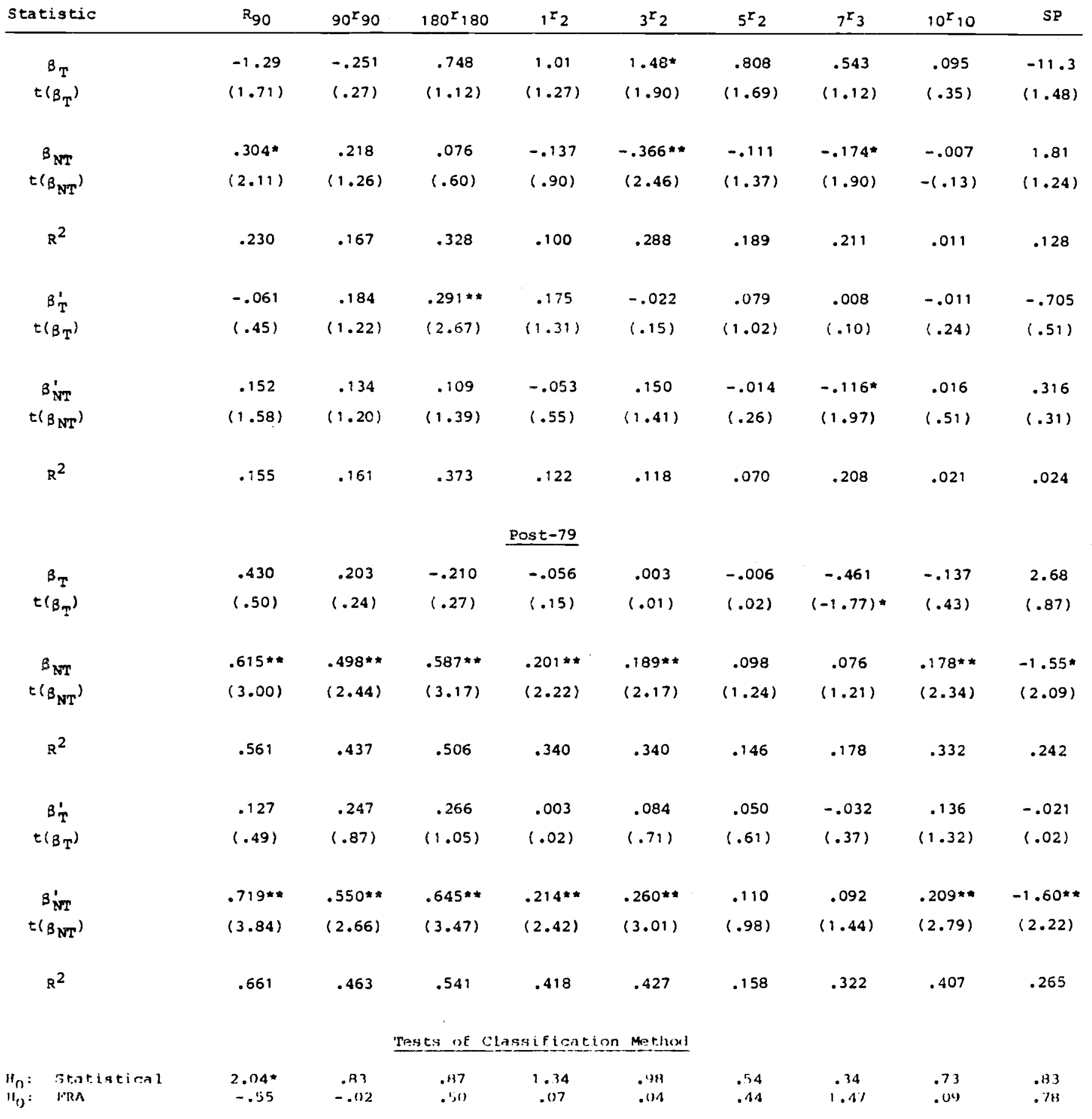

${ }^{a} \mathrm{~N}=18$ for both pee-79 and mit-79 perimis.

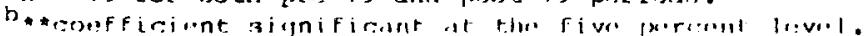

coofficient significant at the ten parcent livel. 


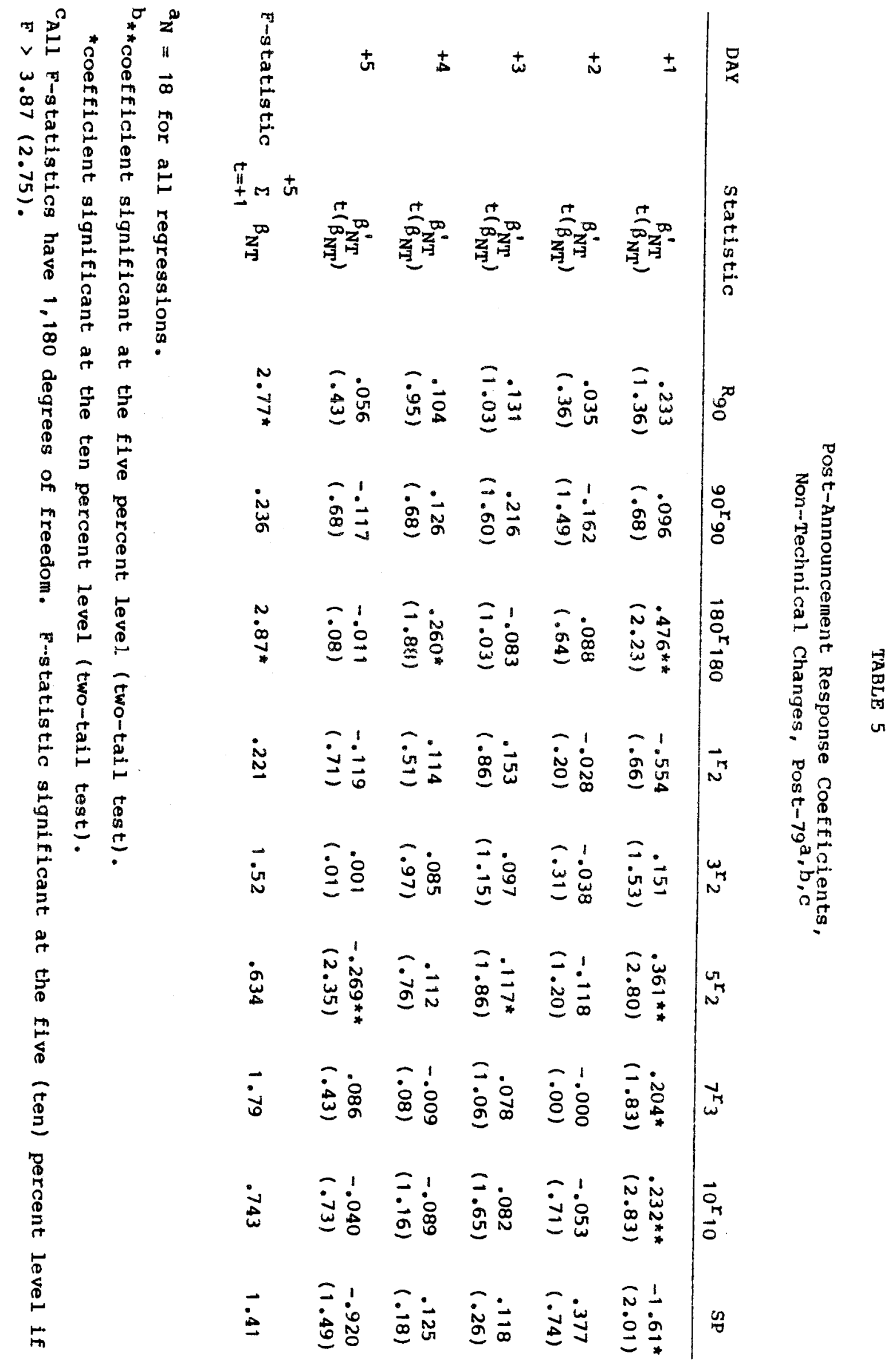


FOOTNOTES

${ }^{1}$ For other studies that have reported significant announcement effects of discount rate changes on a variety of securities markets, see Baker and Meyer (1980), and Brown (1981), as well as those discussed in the text.

2 For a discussion of market efficiency and a review of some relevant literature, see Fama (1970) and Copeland and Weston (1979).

${ }^{3}$ This is a much stronger statement than is actually necessary. Specifically, although a technical change in the discount rate may be known with certainty, its timing may not. Since discount rate changes have real effects, this timing uncertainty may give rise to an announcement effect in some markets even for endogenous discount rate changes. If timing uncertainty is at least as great for nontechnical changes as it is for technical changes, market efficiency would lead us to assert that the announcement effect of a nontechnical change exceeds that associated with a technical change. Our discussion in the text, which can be viewed as assuming no timing uncertainty, is one example of this assertion and, given the empirical findings, simplifies the exposition of the paper. It is important, however, to be aware of the timing issue and to recognize that an announcement effect associated with discount rate changes is appropriately viewed as a necessary but not sufficient condition to assert that the market is inefficient.

4 In principle, one could separate out the numerator and denominator effects of discount rate changes on stock prices. Such an analysis, however, involves rather heroic assumptions and would be, at most, of tangential relevance to our research.

$5_{\text {The forward rate }} x^{r}$ is obtained by the formula $x^{r}=((x+y) / y) R_{x+y}-$ $(x / y) R$ where $R$ is the actual cash market rate on a bond. An alternative $x+y$
approximation to calculating forward rates is presented by Shiller, Campbell and schoenholtz (1983) was shown by Roley and Troll to make little difference.

6 In the post-79 period there was either an imposition of or an increase in a surcharge on discount window borrowing on the same announcement day as three discount rate changes. To control for this, the estimation of all equations over the post-79 period includes a dummy variable equal to one when the surcharge change is announced on the same day as a discount rate change and is zero otherwise. Exclusion of this variable does not change our results.

7 The two rates that do not indicate a response to discount rate changes correspond to the intermediate forward rate $5^{r_{5}}$ used by Roley and Troll. This is also the rate they reported as not being significantly affected by discount rate changes.

${ }^{8}$ The results in Table 2 indicate clearly that the size of the discount rate change is an important determinant of asset price reaction. To examine this finding further, we tested whether only the announcement of a discount rate change, regardless of magnitude, explains asset price reaction. This was done via estimation of the equation. 


$$
\Delta R_{i t}=\alpha_{c} \text { CHANGE }_{t}+\beta \Delta R D_{t}+\varepsilon_{t}
$$

where CHANGE equals +1 if the discount rate increased, -1 if the discount rate decreased, and zero otherwise. If only the announcement matters, we expect $\alpha_{c}>0\left(\alpha_{c}<0\right)$ and $\beta=0$ for interest rates (stock prices). Otherwise we expect $\alpha_{c}=0$ and $\beta$ to be as discussed in the text. In all cases, $\alpha_{C}$ was not significantly different from zero and $\beta$ was similar in magnitude and significance to the results reported in Table 2. This finding provides further support for the specification given in equation (1).

${ }^{9}$ Roley and Troll find that only when the fed funds rate increases by at least 100 basis points is there a significant relationship between changes in the fed funds rate and changes in the discount rate. Further, negative movements in the fed funds rate do not indicate any significant relationship between changes in the fed funds rate and changes in the discount rate.

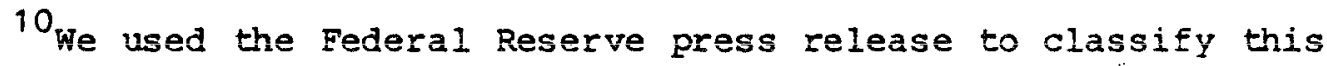
controversial discount rate change, which occurred on February 5, 1975. Classification according to the Wall Street Journal's interpretation made virtually no difference in the results.

${ }^{11}$ There are, however, at least two difficulties that are more severe for the statistical method. In some sense, every week where a discount rate change is not made has a "non-announcement" effect that could effect security prices. This difficulty, of course, will characterize any study of announcement effects when the timing of the announcement is not a priori kinown. Auditionaliy, discount rato shaxges have been 25 , 50 or 1 nn basis points, but predictions of the statistical model may be any amount, so that some predictions of discount rate changes (e.g., 11 basis points) may be unrealistic. It may be more appropriate, then, to view the statistical method as reflecting the probability of a discount rate change multiplied by the size of the expected change. This suggests possibly using a logit model to estimate probabilities of discount rate changes. Such a model would still be characterized by the first difficulty and, further, there is no control for size or direction unless even more complexity is added via a multinomial logit model.

12 The correlation between the percentage of technical components and between nontechnical components across models are equal, and the correlation between the technical and nontechnical components of the models equal in magnitude but of opposite sign to the like correlations, because using percentages normalizes all discount rate changes to be the same size and the two classifications must sum to one.

This, of course, does not hold if magnitudes are used instead of percentages. The former are sensitive to the absolute size of discount rate change. Since it is likely that both technical and nontechnical components will increase with the absolute size of a discount rate change, a positive correlation between the technical and nontechnical classifications of the two methods could result. Even so, we expect the like classifications of the two models to be more highly correlated than the opposite classifications. Using magnitudes, the correlation between technical (nontechnical) classifications of the two models is $.70(.86)$, while the correlation between technical (nontechnical) classifications from the statistical method and nontechnical 
(technical) classification from the FRA method is .50 (.57). This finding further reflects the consistency of the two models.

${ }^{13}$ The data on technical and nontechnical discount rate changes is available from the authors upon request.

${ }^{14}$ The only case where a significant increase (at the five percent level) in explanatory power is not observed using the FRA method is for the $5^{r} 2$ forward rate. When the statistical analysis is employed, the explanatory power of equations using the forward rates $3^{r} 2^{\prime} 7^{r}{ }^{r}$ and $10^{r} 10$ actually declines.

15 one conjecture consistent with the empirical evidence and perhaps with future investigation is the notion that all discount rate changes are technical in nature but the policy authorities choose the discount rate announcement as an opportunity to signal changes in the direction and/or magnitude of monetary policy. Several readers suggested the alternative view, consistent with the above conjecture, that while all discount rate changes are to some extent endogenous, nontechnical changes arise because of changes in or uncertainty about the policy rule or the Federal Reserve reaction function.

${ }^{16}$ Two of these interest rates, $5^{r}{ }_{2}$ and $7^{r} 3^{\prime}$ evidence no announcement effect on day $t$. This finding may be due to relatively thin trading of instruments in this maturity range so that the effect of discount rate changes is not fully reflected in prices until after day $t$. The existence of thin trading also implies abnormal returns could not be earned based on a trading otrategy implemented on day t.

17 This assertion assumes no timing uncertainty, otherwise, as previously noted, an endogenous discount rate genexating an announcement effect is not necessarily an indication of market inefficiency. 


\section{BIBLIOGRAPHY}

Baker, H. and J. Meyer. "Impact of Discount Rate Changes on Treasury Bills," Journal of Economics and Business 32 (Fall 1980), 43-48.

Brown, K. H. "Effect of Changes in the Discount Rate on the Foreign Exchange Value of the Dollar: 1973-1978, " Quarterly Journal of Economics 95 (August 1981), 551-558.

Copeland, T. and F. Weston. Financial Theory and Corporate Policy (Reading: Addison Wesley Publishing Co.), 1979.

Davidson, R. and J. Mackinnon. "Several Tests for Model Specification in the Presence of Alternative Hypotheses," Econometrica 51 (November 1981), 781-793.

Fama, E. "Efficient Capital Markets: A Review of Theory and Empirical Work," Journal of Finance 25 (May 1970), 383-417.

Froyen, R. "The Determinants of the Federal Reserve Discount Rate Policy," Southern Economic Journal 42 (October 1975), 193-200.

Lombra, R. and R. Torto. "Discount Rate Changes and Announcement Effects," Quarterly Journal of Economics 91 (February 1977), 171-176.

Pearce, $n$, and v. V. Roley. "The Reaction of Stock Prices to Unanticipated Changes in Money: A Note," Journal of Finance 38 (September 1983), 13231334 .

- "Stock Prices and Economic News," Journal of Business, forthcoming, 1984 .

Roley, V. V. "The Response of Short-Term Interest Rates to Weekly Money Supply Announcements," Journal of Money, Credit and Banking 15 (August 1983), 344-354.

Roley, V. V. and D. Troll. "The Impact of Discount Rate Changes on Market Interest Rates," Federal Reserve Bank of Kansas City Economic Review (January 1984), 27-39.

Santomero, A. "Controlling Monetary Aggregates: The Discount Window," Journal of Finance 38 (June 1983), 827-844.

Shiller, R., J. Campbell and K. Schoenholtz. "Forward Rates and Futures Policy: Interpreting the Term Structure of Interest Rates," unpublished manuscript, Yale University, 1983.

Urich, T. and P. Wachtel. "Market Response to the Weekly Money Supply Announcements in the 1970's," Journal of Finance 36 (December 1981), 1063-1072.

- "The Structure of Expectations of the Weekly Money Supply Announcement," Journal of Monetary Economics 13 (March 1984), 183-194. 
Waud, R. "Public Interpretation of Federal Reserve Discount Rate Changes: Evidence on the 'Announcement Effect,'" Econometrica 38 (March 1970), 231-250.

Yawitz, J. "An Analytical Model of Interest Rate Differentials and Different Default Recoveries," Journal of Financial and Quantitative Analysis 16 (September 1977), 481-490. 